\title{
O SODOBNEM POMENU GRŠKE ПAIAEIA ZA POJEM URAVNOTEŽENE VZGOJE: ARISTOTEL, NIETZSCHE, CAMUS, HANNAH ARENDT ${ }^{1}$
}

\author{
VALENTIN KALAN
}

Svet brez sveta Grkov je katastrofa. ${ }^{2}$

\section{UVOD}

Sodobni izobraževalni sistemi so nenehno v procesu preurejanja, ki zahteva od nas nov premislek temeljev vzgoje in izobraževanja. Ta proces so mnogi filozofi kulture in vzgoje dojeli kot krizno stanje. Toda že sama percepcija kriznega stanja je mogoča samo v zgodovinski osmislitvi. Kaj je vzgoja in izobrazba, ni mogoče pojasniti z

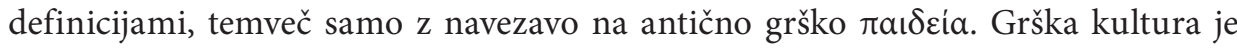
ustvarila tako sistem vzgoje kakor tudi pedagogiko kot Erziehungslehre. ${ }^{3}$ Vračanje $\mathrm{k}$ antični vzgoji je sestavni del evropske vzgojne tradicije. Harmonična povezava gimnastične in glasbene vzgoje je ustvarila 'krasno zgradbo' grškega duha, primerljivo umetnosti in znanosti. Zato je pajdeja tipičen fenomen, 'tip', za zgodovinsko spoznanje.

Grško-rimska kultura je bila v celoti nekakšen sistem vzgoje in izobraževanja. Zato ni težko najti vse polno izrekov o pomenu vzgoje. Za Heraklita je bila vzgoja »drugo sonce« (DK 134), za sofista Antifonta je bilo izobraževanje in vzgajanje,

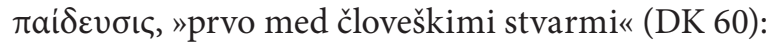

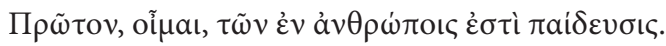

Najvažnejše na svetu je po mojem mnenju vzgoja. ${ }^{4}$

\footnotetext{
1 Ta sestavek je izšel iz referata z naslovom »On the contemporary Relevance of Greek Paideia for the Concept of a balanced Education: Aristotle, Nietzsche, Camus, H. Arendt«, ki je bil prebran na 19. mednarodnem filozofskem simpoziju na temo Paideia: education in the global era. Potekal je od 15. do 21. julija 2007 na Samosu, organizirala sta ga The International Association of Greek Philosophy in The International Center of Greek Philosophy \& Culture.

2 Heidegger, Reden und andere Zeugnisse, 73.

3 Dilthey, Pädagogik, 21 in 36.

4 Prevod Anton Sovrè (fr. 7).
} 
Platon, čigar celotno filozofijo je mogoče opazovati z vidika vzgoje, je štel vzgojo za nekaj najbolj božanskega, posvetovanje o njej pa za sveto stvar (Theages 122b5-6).

Ovrednotenje zgodovinskega raziskovanja vzgoje je tesno povezano $\mathrm{z}$ našim lastnim razumevanjem zgodovinskega bivanja. $\mathrm{Z}$ metodološkega vidika sta za to temo posebno pomembni Nietzschejeva teorija »skrite zgodovinskosti« in Husserlova ideja »univerzalne zgodovinskosti, $\aleph^{5}$ razvita v 2. delu Krize evropskih znanosti. Tu se je Husserl soočil z vprašanji stopenj zgodovinskosti, z odnosom med generacijami in smislom, s pomenom tradicije in s pomenom grškega 'čudeža' za Evropo.

Pozni Husserl izhaja iz tega, da je človeški kulturni svet vedno zgodovinski svet: „Sleherni človeškosti v skladu z njenim bistvom ustreza nek kulturni svet kot življenjsko okolje v svojem načinu biti, ki je v vsakem zgodovinskem času in človeškosti vsakokratno in je ravno določena tradicija. Nahajamo se torej v zgodovinskem horizontu, v katerem je, kakorkoli malo določenega že vemo, vse zgodovinsko. « ${ }^{6}$

Bistveni sestavni del kulturnega sveta je seveda $\pi \alpha \_\delta \varepsilon \dot{\alpha}$. Nekega danega kulturnega dejstva ne moremo razumeti, če ne spoznamo njegove zgodovinskosti. Vsaka kulturna sedanjost je totaliteta, ki implicira kontinuiteto medsebojno implicirajočih se preteklosti: »In ta celotna kontinuiteta je enotnost tradicionalizacije, ki sega vse do sedanjosti, ki je naša, in je kot tradicionaliziranje nje same v tekoči-stoječi življenjskosti.."

$\mathrm{H}$ kulturi spada prenašanje tradicije, prenašanje izročila, in to je vzgoja. Kulturna zgodovina tako postane živo gibanje izvornega ustvarjanja in ohranjanja Husserl pogosto pravi sedimentiranja - smisla. In pristna filozofija vzgoje je $\mathrm{v}$ tem, da obstoječe pedagoške teorije - "zgodovinsko dane tvorbe smisla" - spremljamo nazaj "vse do zaprte dimenzije praevidenc, ki so njihova osnova« ${ }^{8}$

$S$ tem je fenomenologija dokončno presegla naturalizem in objektivizem zgodovinopisja. Filozofija vedno vključuje, ker je zgodovinska, tudi dimenzijo preteklosti: »Filozofija s časovnim obzorjem svetovne preteklosti (našega sveta) je sedanja (sedaj resnična) filozofija, kakor je nastala iz svojih preteklosti.«"

Tudi človek kot posameznik živi v zgodovinskem svetu, ki je posredovan $\mathrm{v}$ tem smislu, da se generacijska povezanost med ljudmi in podružabljanje človeštva dogaja kot nenehno kultiviranje na podlagi že kultiviranega. ${ }^{10} \mathrm{~V}$ razpravi »Zgodovina filozofije v kontekstu historične znanosti in kulture, November 1934« Husserl nasproti materialističnim filozofom različnih observacij poudari, da človek ne živi »v svetu kot materija«. Posamezno človekovo bivanje, ki je vselej tudi že bivanje v »historičnosti«,

\footnotetext{
Husserl, »Pismo Ingardnu« (31. 12. 1936); gl. Husserl, Krisis, Ergänzungsband, xiv. Prevodi iz Husserla razen razprave »Vprašanje po izvoru geometrije«: V. K.

6 Husserl, „Vprašanje po izvoru geometrije«, 21, in Krisis, 378.

Husserl, Krisis, 379, in »Vprašanje po izvoru geometrije«, 22.

Husserl, Krisis, 380, in »Vprašanje po izvoru geometrije«, 24.

Husserl, Krisis, Ergänzungsband, 49.

10 Husserl, Krisis, 382.
} 
je vedno duhovno, jaz-ovsko bivanje v individualni časovnosti. Časovni razponi preteklost, sedanjost in prihodnost so medsebojno povezani, a tako, da se mora prihodnost zasnavljati $" \mathrm{Z}$ indukcijo « iz preteklosti. ${ }^{11} \mathrm{Na}$ ta način moremo reči, da se tudi sodobno izobraževanje, ki išče novih začetkov, more 'inducirati' ravno ob svojih

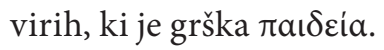

Govorimo o odkrivanju grške pajdeje, ker želimo paziti na razliko med odkrivanjem in raziskovanjem. Filozofija ni samo raziskovanje in argumentiranje, temveč je 'znanost o resnici'. Ob odnosu do resnice pa nismo samo v drži raziskovanja, temveč odkrivanja, in ne samo v drži spoznavanja, temveč tudi bivanja. Grška beseda za resnico à $\lambda \dot{n} \theta \varepsilon ı \alpha$ pomeni tudi neskritost. Po znamenitih Heideggrovih meditacijah to pomeni, da resnica ni samo pravilnost izrekanja, temveč fenomen, ki ima mnogo nasprotij. Eno od nasprotij resnice je pozaba, $\lambda \dot{\eta} \theta \eta$. O odkrivanju grške filozofije moremo govoriti tedaj, ko opazimo, da je v sodobni filozofiji marsikaj, kar je ostalo zakrito, pozabljeno, skrito.

Toda preteklost kot del naše zgodovinskosti ima nasploh značilnost, da se skriva. To je opazil Nietzsche v Veseli znanosti, kjer je govoril o »skriti zgodovini«, ki more dobiti svojo osvetlitev šele iz sedanjosti: »Historia abscondita. - Vsak velik človek ima silo, ki deluje za nazaj: zaradi njega ... se tisoč skrivnosti preteklosti priplazi iz svojih zatočišč - naprej v njegovo sonce. $\aleph^{12}$

Naše vprašanje zdaj je, katere so tiste stvari, ki jih moderno izobraževanje rabi, pogreša in ki jih je nemara prezrlo v antični grški kulturi. Gotovo je mnogovrstnost naših odnosov do Grkov posledica mnogoplastnosti naše lastne zgodovinskosti. Toda katere so zgodovinske strukture naše sedanje vzgoje, ki zbujajo potrebo po grštvu? Odgovor na to bom iskal pri treh filozofih, ki so merodajni za razumevanje sodobne kulture in tudi za mesto izobraževanja v njej. To so Hannah Arendt, Camus in Nietzsche. Za grško razumevanje pajdeje pa se bomo zaustavili pri manj poznani Aristotelovi filozofiji vzgoje.

\section{FENOMENOLOŠKI PRISTOP K ARISTOTELOV PEDAGOGIKI}

Aristotelova teorija vzgoje pogosto ne najde primerne ocene $\mathrm{v}$ zgodovini vzgoje, čeprav je Aristotel vzgoji namenil večjo pozornost, kot se običajno misli. ${ }^{13}$ Aristotel se je loteval vprašanj vzgoje $z$ več vidikov, katerih medsebojna povezanost ni takoj opazna. To je tudi eden od razlogov, da je njegov pojem $\pi a t \delta \varepsilon i ́ a$ manj poznan in da Jaegrovo delo Paideia o Aristotelu ne govori. ${ }^{14}$

Aristotelova ideja $\pi \alpha \iota \delta \varepsilon i a$ je vsebovana v njegovem pojmu narave in biti. Narava

\footnotetext{
11 Husserl, Krisis, Ergänzungsband, 4.

12 Nietzsche, Vesela znanost, 66.

13 Lichtenstein, »Aristoteles«, 327.

14 Fortin, »Paradoxien«, 256.
} 
je v procesu gibanja in spreminjanja, spreminjanje je razloženo po zgledu tehnične produkcije kot smotrno dogajanje. Tako je narava $\mathrm{v}$ stalnem procesu postajanja,

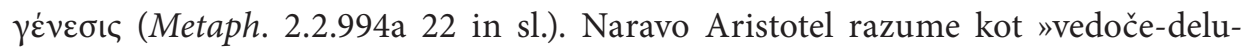

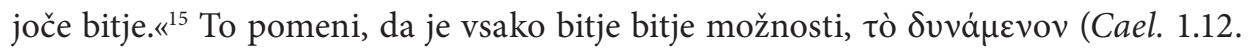
282a 8). ${ }^{16}$ Umetnost $z$ ene strani posnema naravo, z druge strani pa dopolnjuje ( $\dot{\varepsilon} \pi$ $\tau \varepsilon \lambda \varepsilon i v)$ stvari, ki jih narava ne zmore izdelati (Ph. 2.8.199a 15). Tako dobimo plodno analogijo med naravo in umetnostjo, ki velja tudi za razmerje med naravo in vzgojo. V Politiki je izrecno določeno, da ne le umetnost, temveč tudi vzgoja dopolnjujeta naravo:

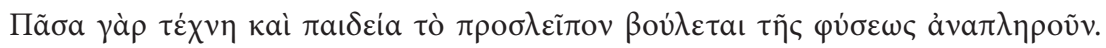
(Politika, 7.17.1337a 1-3)

Vsaka umetnost in vsaka vzgoja hoče izpolniti to, kar naravi manjka, da bi bila narava.

Aristotelova teorija telesne, moralne in politične vzgoje in izobrazbe (Nikomahova etika in Politika) je utemeljena na pojmu naravnega razvoja vsakega bitja. To izhodišče je ostalo temeljna supozicija tako imenovane naravne pedagogike. To je vidno tudi v določitvi vzgoje, ki jo je Aristotel dal po diskusiji s kini-

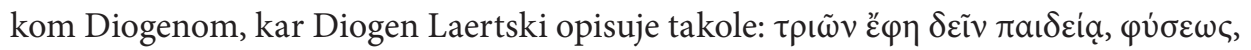
$\mu \alpha \theta \dot{\sigma} \sigma \varepsilon \omega \varsigma$, ả $\sigma \kappa \eta \dot{\sigma \varepsilon \omega \varsigma}$. (Za izobraževanje so potrebne tri stvari: narava, znanje in poučevanje. $)^{17}$ Kakor za Platona ima tudi za Aristotela filozofija pedagoški karakter. Tako pravi v Retoriki za Aleksandra, da je vzgoja priznani varuh duše ( $\psi v \vee \eta \tilde{\eta} \varsigma ~ \varphi v \lambda \alpha-$ $\kappa \tau$ $\leftarrow$ óv), in »da je razum, povezan z vzgojo, vodnik življenja« ( $\dot{\eta} \gamma \varepsilon \mu \dot{\omega} v \dot{\varepsilon} \sigma \tau \iota$ ßíov). ${ }^{18}$

Zlasti retorika in dialektika imata pomen za višjo splošno izobrazbo in sta včasih vzeti za predstopnjo znanosti. ${ }^{19}$ Propedevtični značaj so imeli zlasti Aristotelovi dia-

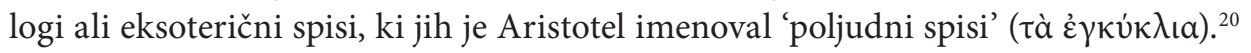

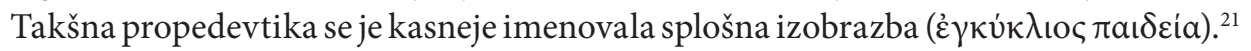

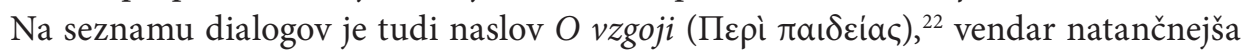
vsebina ni poznana. Eden od dialektičnih toposov glede vzgoje nastopa $\mathrm{v}$ Retoriki: to je topos na osnovi konsekvence, ki naj spodbudi ali odsvetuje izobraževanje: »Slábo,

\footnotetext{
5 Lichtenstein, »Aristoteles«, 325.

16 Pozni Nietzsche je govoril o sebi kot 'dinamitu'.

17 D. L. 5.18.

18 Rh. Al. 1.1421a 17-18, 24.

19 R. Meister, »Die Entstehung«, 29.

20 EN. 1.5.1096a 3.

${ }_{21}$ Quint. 1.10.1. Meister, »Entstehung«, 29; Mette, »ЕГКҮК $\Lambda$ IO $\Sigma$ ПАI $\Delta$ EIA«, 39.

22 D. L. 5.22.
} 
ki sledi izobraženosti, je utrpevanje zavisti, dobro je to, da smo modri.. ${ }^{23} \mathrm{Z}$ vzgojo ljudje dosežejo razumnost in tako morejo živeti v resnici. ${ }^{24}$ Vzgoja tudi doseže, da so

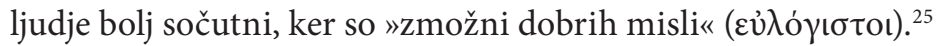

Temeljno strukturo vzgoje sestavlja pri Aristotelu t.i. 'pedagoški ternar' ali peda-

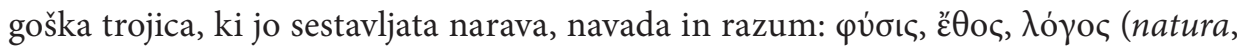
usus, ratio). Tako pravi v Politiki: "So tri stvari, skozi katere ljudje postanejo dobri in odlični: te tri stvari so narava, navada in razum. ${ }^{26} \mathrm{~V}$ Nikomahovi etiki je ta trojica

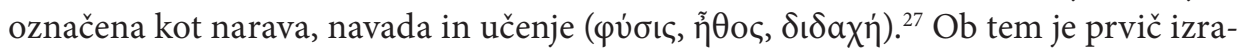
žena ideja splošne pedagogike, kajti tudi vzgoja se mora nanašati na splošno in na to kar je skupno. ${ }^{28}$

Vzgoja je nujna za obstoj države, ker je naravno nujen prenos kulture od generacije na generacijo:

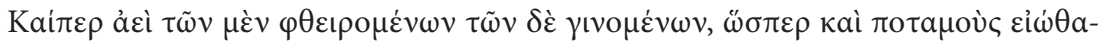

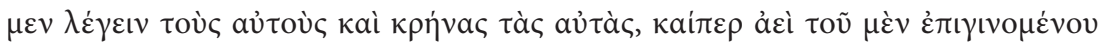

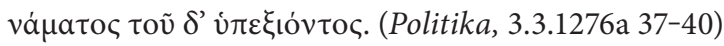

Čeprav vedno nekateri umirajo in se drugi rojevajo, kakor je naša navada reči, da so reke in izviri isti, čeprav vedno en tok prihaja in drugi odteka.

Vprašanje filozofske vzgoje Aristotel obravnava v razpravi o razumskih vrlinah. Nekdo ne more postati razumen brez izkustva. Zato mlad človek ne more postati

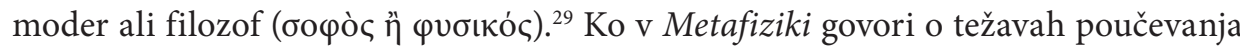
filozofije, priporoča, da upoštevamo značaj poslušalcev in da izhajamo od tistega, kar je bolj poznano. ${ }^{30}$ Poleg tega je treba znati oceniti, kdaj je treba govoriti na matematičen način, kdaj pesniško in kdaj je treba biti pozoren na stopnjo natančnosti, ki jo neka znanost dopušča: "Zaradi tega je treba že biti izobražen o tem, kako je posamezne stvari treba sprejemati, saj je nespametno hkrati iskati določeno znanost ter obrat znanstvenega postopka; sicer pa nobeno od obojega ni lahko doseči. «11 Filozofija pomeni biti v resnici glede principov. Toda pot do principov ni dokaz. Zato Aristotel pravi, da aksioma o protislovju ni mogoče dokazati, ker je sam načelo za vsako dokazovanje. Zahteva, da bi bilo to načelo dokazano, kaže pomanjkanje

\footnotetext{
${ }^{23}$ Rh. 2.23.1399a 11 in sl. Vsi prevodi iz Aristotelovih del: V. K.

24 Rh. 2.6.1384a 34.

25 Rh. 2.8.1385b 27.

26 Pol. 7.12. 1332a 39-40.

27 EN 10.9.1179b 20-21.

28 EN 1180b 15; Ballauff, Pädagogik, 114.

29 EN 6.8.11442a 17 in sl.

${ }^{30}$ Metaph. 2.3.994b 32.

${ }^{31}$ Metaph, 2.2.995a 12-14.
} 


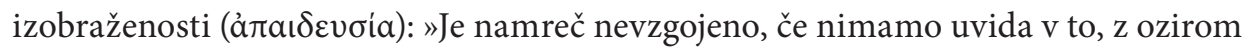
na katere stvari je treba iskati dokaz in glede na katere to ni potrebno. ${ }^{32}$

Aristotelov pojem filozofske izobraženosti ali kulture ( $\pi a \iota \delta \varepsilon i a$ in $\pi \alpha i \delta \varepsilon v \sigma \iota \varsigma)$ je najbolj artikuliran v spisih Deliživali, Topika, Metafizika, Evdemova etika in Nikomahova etika. V znamenitem uvodnem poglavju razprave $O$ delih živali je Aristotel glede vsake znanstvene stroke ( $\mu \varepsilon \dot{\varepsilon} \theta \delta \delta \varsigma)$ razlikoval med dvema držama ( $\varepsilon \xi \xi_{\iota \varsigma)}$ : ena drža je

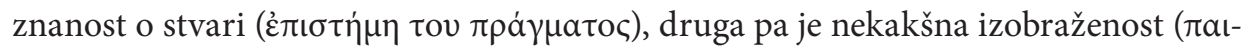

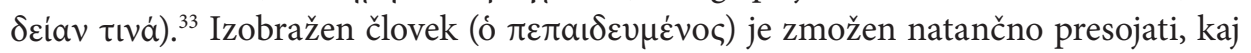
je govorec podal prav in kaj ne. Izobraženec je poleg tega zmožen pravilno presojati (крıтıкóv) tako rekoč o vsem. ${ }^{34}$

Sposobnost vzgojenega v filozofiji je presoja, kritika (крiveıv), kar je nekaj drugega kot 'splošna izobrazba'. ${ }^{35}$ Nevzgojenost je neke vrste slepota, je tako, kot da bi nekdo, ki je od rojstva slep, razmišljal o barvah. Njegov govor bi se nanašal na besede in ne bi imel miselne vsebine. Vzgojenost pa je zmožnost "razločevati, kaj je spoznavno skozi samega sebe in kaj ni« ${ }^{36}$ Ta presoja je vpogled v stvar.

Vprašanje filozofske vzgoje je zelo pomembno za določitev statusa etike in politike. Kajti področje etike in politike je področje kontingence, v katerem ni stroge zakonitosti, temveč le večja ali manjša pravilnost in verjetnost dogajanja: gre za

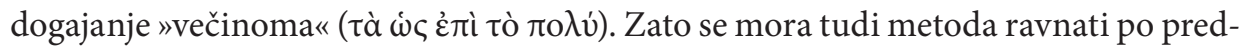
metu. Etika ima lahko samo toliko natančnosti, kolikor jo dopušča narava predmeta

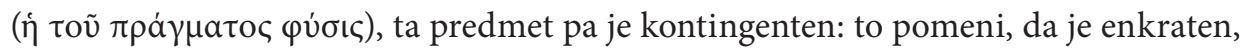
konkreten in spremenljiv. Etika zato ne more imeti istega statusa kakor matematika. Taka presoja je stvar filozofske vzgoje: »Vsakdo presoja prav stvari, ki ji pozna, in je o njih dober presojevalec. O posameznem področju torej tisti, ki ima izobrazbo o njem, absolutno prav pa nekdo, ki je izobražen o vsem (ó $\pi \varepsilon \rho \grave{~} \pi a ̀ v ~ \pi \varepsilon \pi \alpha ı \delta \varepsilon v \mu \varepsilon \dot{v o \varsigma})$ «. ${ }^{37}$

Vprašanje vzgoje je pomembno tudi pri določitvi sreče. Aristotel razlikuje tri drže glede tega, ki tvorijo tri načine življenja: življenje uživanja, politično življenje in teoretsko življenje. ${ }^{38} \mathrm{~V}$ Evdemovi etiki so med dobrinami, ki jih izbiramo, omenjene čast, slava, bogastvo in vzgoja. ${ }^{39}$ Vzgoja je $v$ Nikomahovi etiki omenjena samo posredno, ko Aristotel pravi, da tisti, ki se zavedajo svoje nevednosti, občudujejo tiste,

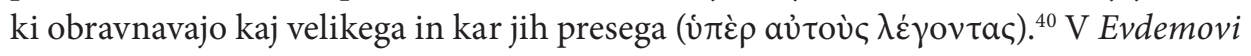
etiki zastavlja vprašanje, kako doseči dobro življenje in srečo: ali po naravi ali skozi

\footnotetext{
Metaph. 3.3.1005ab 3-4, 1006a 7 in sl.

$P A$ 1.1.639a 1 in sl.

PA 1.1.639a 1 in sl.

Fortin, »Paradoxien«, 265 in sl.

Ph.2.1.193a 3-9.

EN 1.1.1094b 27-5a2

EN 1.3.1095b 17 in sl.

EE 1.2.1214b 9.

40 EN 1095a 25.
} 


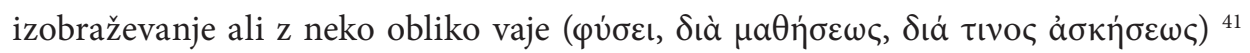
Poleg tega Aristotel omenja še dve drugi možnost, da se pride do sreče, to sta božji navdih in sreča: »Kakor tisti ljudje, ki so prevzeti od nimf ali bogov in so tako iz sebe zaradi navdiha nekega božanstva, ali pa zaradi sreče? «2

Ob vprašanju dobrega Aristotel postavi tudi vprašanje poti (ódóc) do principov. Pri tem razlikuje med razmišljajočo potjo, ki začenja od principov, in med izkustveno potjo, ki vodi do principov. S tem navezuje na Platona, ki je o tem razpravljal v Državi in v predavanju $O$ dobrem, o katerem je poročal tudi Aristotel. Aristotel sedaj ta postopek primerja s tekom na stadionu, ${ }^{43}$ kjer se teče od športnih sodnikov 'atlotetov', do konca in nazaj. ${ }^{44}$

Po Aristotelu je v etiki treba začeti od tega, kar je nam poznano. Za filozofsko etiko je prvi pogoj ta, da nas dobro vodijo navade ( $\varepsilon^{\prime} \theta \varepsilon \sigma \iota$ ñ $\left.\chi \forall \alpha \iota\right) .{ }^{45}$ Tu gre za vzgojo, ki je že filozofija. Svojo filozofsko vzgojo zoperstavlja sofistični vzgoji. Tako pravi v delu De sophisticis elenchis: »Sofisti domnevajo, da morejo vzgajati tako, da nudijo ne umetnost, temveč rezultate umetnosti. ${ }^{46}$ Sofistično poučevanje $(\delta\llcorner\delta \alpha \sigma \kappa \alpha \lambda i \alpha)$ zato ni primerno za metodično ravnanje $\mathrm{v}$ znanosti. Na sredi med izkustvom in znanostjo je vzgoja, ki uravnava napredek znanosti. To Aristotel ponazori z medicino. ${ }^{47}$ Pajdeja nam tako pomaga, da dosegamo resnico glede počel, »da smo v resnici glede načel «

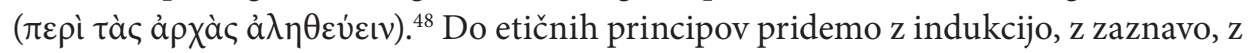
navado, ${ }^{49} \mathrm{v}$ teoretskih znanostih pa $\mathrm{z}$ umom. ${ }^{50}$ Niti v etiki niti v teoretskih znanosti

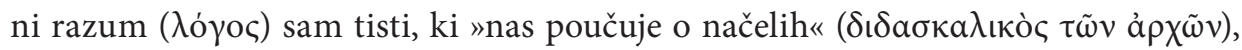
temveč je to posebno zadržanje, posebna vrlina: »Vrlina, bodisi naravna ali priučena je to, kar nas more učiti, da pridemo do pravilnega mišljenja o principu« ( $\delta$ เ $\delta \alpha \sigma \kappa a-$

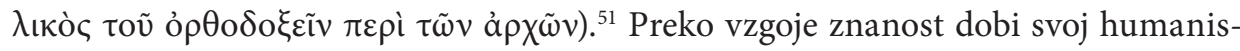

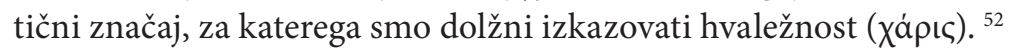

Tako je Aristotelova filozofska izobraženost povezana z dialektiko, analitiko, retoriko, prvo filozofijo, politiko, etiko in estetiko.

\footnotetext{
EE 1.1.1214a 16 in sl.

${ }^{42}$ EE 1.1.1214a 23.

$43 \mathrm{Na}$ to je opozoril Willmann, Aristoteles als Pädagog, 200.

${ }^{44}$ EN 1.4.1095 b1.

45 EN 1095b 4.

46 SE 34.184a 3.

47 Pol. 3.6.1282a 1 in sl.

48 EN 6.7.1141a 18.

$49 \quad$ EN 1.7.1098b 4.

50 APo. 2.19.100b 12 in sl.

${ }^{51}$ EN 7.8.1151a 17-19.

${ }^{52}$ SE 34.184b 8.
} 


\section{NIETZSCHEJEVE IDEJE O IZOBRAŽEVANJU}

V svojem nastopnem govoru na Univerzi v Baslu 28.5.1869 z naslovom »Homer in klasična filologija« Nietzsche uvede širok pojem klasične filologije, ki obsega zgodovino, kolikor skuša razumeti spomenike določene ljudske individualnosti, naravoslovje, kolikor skuša utemeljiti jezikovni instinkt, in estetiko, kolikor skuša vzpostaviti klasično antiko kot večno veljavni vzorec sedanjosti (11.2). Če je klasična antika jamstvo, da Evropa ne zapade v barbarstvo, pa takega jamstva ne morejo dati filologi, temveč samo umetniki in umetniško nadarjene narave, ki edini »morejo čutiti, kako meč barbarstva visi nad glavo vsakega posameznika, ki izgubi izpred oči nedopovedljivo enostavnost in plemenito dostojanstvo helenskega« (11.3). Antike ne more nadomestiti »noben še tako sijajen napredek tehnike in industrije, še tako sodobna organizacija šolstva, še tako razširjena politična izobrazba množice.« (ibid.)

V Rojstvu tragedije Nietzsche prvič razvije idejo o grška kulturi kot sredini sveta. Pri oblikovanju sveta so možni trije pristopi, ki jih Nietzsche označi kot sokratsko, umetniško in tragično kulturo; te so v zgodovinskih konkretnosti: aleksandrijska ali rimska, grška in indijska ali budistična kultura (1.116). Indijska kultura je šla od orgiazma $\mathrm{k}$ budizmu in ekstatičnim stanjem in ne pozna umetnosti, rimska kultura se je razvijala v smeri skrajnega posvetovljenja, ki ga vidimo ob rimskem imperiju (1.133). Nietzsche se je želel izogniti ne le ekstatičnemu tuhtanju, temveč tudi izčrpavajočemu hlastanju po svetovni oblasti in časti. Budistična kultura po Nietzscheju ne pozna umetnosti. Tako pridemo do grške kulture. Dokaz za pomen grške kulture je v tem, da v sodobnem svetu doživljamo pojave, »ki so tako osupljivi, da bi nepojasnljivi lebdeli v zraku, če jih preko mogočnega obdobja ne bi mogli navezati nazaj na grške analogije« (1.446). Na področju filozofije, umetnosti in znanosti vidimo razpršen duh helenske kulture. Nadaljnja navezava na grško kulturo rabi Proti-Aleksandre: "Zemlja, ki je bila doslej že dovolj orientalizirana, spet hrepeni po helenizaciji. «" To Nietzschejevo idejo bomo zdaj uporabili na njegovo razumevanje izobraževanja.

Nietzschejeve ideje o vzgoji in kulturi so programsko predstavljene v njegovih dveh zgodnjih delih: v predavanjih O prihodnosti naših izobraževalnih zavodov in $\mathrm{v}$ zapisih Mi filologi.

V prvih mesecih leta 1872, po objavi Rojstva tragedije, je imel Nietzsche pet javnih predavanj o vprašanjih izobraževanja $z$ naslednjimi datumi: 16. januar, 6. in 27. februar ter 5. in 23. marec 1872. Imela so velik odmev. Nietzsche sam je predavanja imenoval spodbujevalna in - v primerjavi z Rojstvom tragedije - "popularna ali eksoterična «. ${ }^{54}$ Zadnjega predavanja, ki bi moralo podati »konkluzijo, « Nietzsche ni imel: to je Burckhardt pogrešal, saj naj bi to predavanje dalo »nekakšno rešitev« na tako »objestno in veliko« navržena "vprašanja in pritoževanja.${ }^{55}$ Osrednja tema

53 Nietzsche, Geburt, 447.

54 Benders in Oettermann, Chronik, 263.

55 Benders in Oettermann, Chronik, 264. 
predavanj je klasična antika, a ne kot predmet spoznanja, temveč kot sredstvo vzgoje. Klasična šola ne more podati resnične narave antike: za to je nujna dejavnost pravega vzgojitelja, ki bi bil filozof. Predavanja so tudi Nietzschejevo osebno pričevanje o stanju tedanje nemške kulture. ${ }^{56}$

V njih predavanjih se je dotaknil vseh stopenj nemškega izobraževanja: govoril je o osnovni šoli, o realni šoli, o gimnaziji in o univerzi. Želi prenovo sistema, da bo hkrati star in nov (645). Obstoječi izobraževalni proces vidi kot proces »širjenja vzgoje« in proces njenega zmanjševanja in oslabitve.

Temu nasproti zahteva zožitev in koncentracijo ter krepitev in samozadostnost (647). Ugotavlja potrebo po totalnem preoblikovanju izobraževalnih zavodov, govori o tabelah in uredbah $\mathrm{v}$ šolstvu in zahteva nove tabele. Na ta način želi zbuditi občutek za »specifičnost našega sodobnega nemškega barbarstva« (650) ter apelira na velikodušnost v dejavnosti preoblikovanja šolstva. Ob tem navaja Aristotela, ki pravi

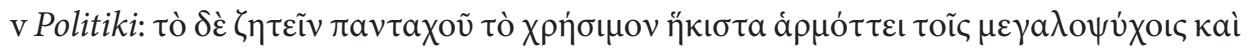

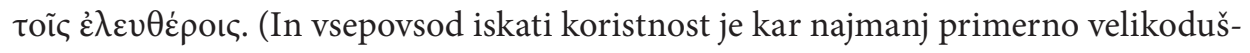
nim in svobodnim ljudem. $)^{57}$

$\mathrm{V}$ prvem predavanju je podvržena kritiki prevladujoča ideja o vzgoji in izobrazbi, kakršna sledi »nacionalno-ekonomskim dogmam sedanjosti« (667): čim več spoznanja in vzgoje, čim več produkcije in potreb - kar največ sreče. Takšna vzgoja ima za cilj uporabne, »kurantne« ljudi. Izobrazba hoče biti hitra in splošna, kar pa z drugega gledišča pomeni zmanjševanje izobrazbe. Zato je za Nietzscheja takšna izobrazba že nekakšno barbarstvo (668): najbolj vsesplošna izobrazba je ravno barbarstvo (»die allerallgemeinste Bildung ist eben die Barbarei«). Zmanjševanje izobrazbe nastopa tudi v znanstveni delitvi dela. Učinek take izobrazbe je viden v žurnalistiki (671). Nasproti izpraznitvi neohumanistične izobrazbe, ki jo je zasnoval Humboldt, Nietzsche vztraja pri tem, da je svet tega, kar je grško, samolastna izobraževalna domovina (»die eigentliche Bildungsheimat«).

$\mathrm{Ob}$ analizi tedanje pedagoške literature Nietzscheja prevzame občutje zgroženosti: filozofija ne sme več začeti »s čudenjem, temveč z zgroženjem « (»Erschrecken «, 673). Svoje poglede na vzgojo začenja s kritičnim prikazom tedanje klasične gimnazije. Med tremi sestavinami gimnazijske izobrazbe (izobrazba, znanje in žurnalistika) ni več enotnosti. Izobrazbena gesla, kot so »klasična izobrazba«, »formalna izobrazba« in »izobrazba za znanost«, nimajo enotnosti, gimnazijski absolvent je »izobrazbeni tragelafos« (682). Pogosto nastopa povezava "učenosti z barbarstvom okusa, znanosti z žurnalistiko« (685).

Zagovor klasične izobrazbe pa preide v zagovor materinskega jezika. Prava klasična izobrazbo je »umetniško resna in stroga navada na rabo maternega jezika» (685-686). Umetniška raba maternega jezika pa ne pride do svojega poleta, če ne

56 Gl. Collijevo spremno besedo k Nietzschejevim zbranim delom; Nietzsche, Geburt, 915.
57 Pol. 8.2.1338b 3-4. 
znamo razlikovati med obliko in barbarstvom, če ne dobimo poleta, ki nas nosi do "prave in edine izobrazbene domovine, do grške antike« (686). Tedaj prevladujoče komentiranje in parafraziranje grških in latinskih klasikov je za Nietzscheja »skok tjavendan« (»Sprung ins Blaue«, 687)..$^{58}$ Delovati proti domnevni kulturi sedanjosti je mogoče samo tedaj, ko nam gimnazija razvije občutje za klasično-helensko (687). Klasična izobrazba more ustvariti dvojen občutek: občutek za sveto resnobo umetnosti in občutje, ki ga ustvarijo klasični jeziki: to je »respekt pred jezikom«, »sveta groza pred jezikom« (676). Do odtujenega helenskega sveta (689) pa ne moremo priti tako, da bi zanikali nemškega oz. nacionalnega duha. Za sodobno nemško kulturo je značilen kozmopolitski agregat (690). Priti je treba do »zelo skrivnostne in težko dojemljive vezi med nemško bitjo in grškim genijem" (691). Romarsko središče (»Wallfahrtsstätte«) za ohranitev grške domovine mora biti delo najboljših in najnadarjenejših ljudi. Samo tedaj bo roka grškega genija lahko nudila »trdno oporo v reki barbarstva« (691).

"Klasična izobrazba" ne more zrasti iz sedanjih izobraževalnih aparatov (»Bildungsapparate«), po drugi strani je klasična izobrazba danes evfemizem za pretenciozno iluzijo. (693) Ni še odkrito izhodišče za višjo izobrazbo, ki bi bila zgrajena na »stebrih antike«. Sedanja gimnazija nima več sil za boj z barbarstvom: »Resnična obnova in očiščenje gimnazije« more priti samo iz pogleda v grško domovino (695). Ljudsko izobrazbo šteje med »saturnalije barbarstva« (698) in želi aristokratsko kulturo. Kljub temu pa meni, da je resnična »judska izobrazba« tisto zdravilno spanje ljudstva in njegovo nezavedno (»Unbewußtsein«, 699), ki omogoča rojstvo visoke kulture. Genij rabi mater, ljudstvo, čeprav ima tudi svoj »metafizičen izvor, nekakšno metafizično domovino " (699). Singularnost in nedostopnost helenske antike je takšna, da ocenjuje marsikatere postopke filologov neprimerne; na primer tega, da z nezaupljivim očesom policaja iščejo protislovja, celo senco protislovij pri Homerju (701).

Težava pri razumevanju grške antike je tudi v tem, da je mnogim nelagodno ob misterijskih in orgiastičnih straneh antike. Mnogi filologi priznavajo samo razsvetljenega Apolona, tako da v Atencih vidijo nekoliko nemoralne apolinike (702). Mislijo, da bodo potegnili resnico iz vodnjaka z ảvá in katá. Filologi ne znajo postaviti pokonci potopljenih, prevrnjenih kipov grške antike. Zato se dogaja, da se antika razbije na kose $\mathrm{z}$ ravno dejavnostjo filologov samih (703). ${ }^{59}$

Ob tako velikih ambicijah Nietzsche postaja neprizanesljiv do učiteljev na gimnazijah, češ da so odtujeni klasični tendenci. Za učitelja klasične izobrazbe grščina in latinščina nikoli ne moreta biti en jezik poleg drugega (704). Nietzsche tudi dvomi, da bi državno širjenje klasične gimnazije doseglo to, kar on želi. Ne ustreza mu poli-

\footnotetext{
Thouard, »Le centaure philologique«, 159.

59 Prav tam.
} 
tika, ki hoče iz države narediti »mistagoga kulture« (707): to mu velja za konservativno heglovstvo.

Sedanja gimnazija zavrača aristokratsko kulturo (712). Najplemenitejši »nemški duh « je z najplemenitejšo potrebo navezan na Grke. Resnična izobrazba (714) je nasprotje svetu nujnosti, je eterična boginja proti koristni dekli, medtem ko so sodobne izobraževalne institucije zasnovane kot sredstvo za premagovanje življenjske stiske. Ob naravoslovni izobrazbi in njenem premagovanju narave z zvijačo (»Überlisten der Natur«, 717), ne smemo izgubiti izpred oči »metafizične enosti vseh stvari«.

Za presojo sodobne izobrazbe je odločilno nasprotje med dvema vrstama ustanov, med ustanovami izobrazbe in ustanovami življenjske nujnosti - to je pravo nasprotje. Obstajata dve poti izobraževanja, pot institucij in potreba po resnični izobrazbi, ki vodi do vzgoje genija. Ta pot (»Bahn«) ima polet, o katerem govori Platon govori v Fajdrosu: to je polet, ki dušo ob stiku z lepoto okrili in jo dvigne do kraljestva čistih enostavnih pralikov stvari (730). Ob ideji resnične izobrazbe Nietzsche postane platonik: išče moderno sonce izobrazbe (»Bildungssonne«, 723).

Resnična izobrazba mora izhajati od vsakdanjih izkušenj in doživetij, ki so najbolj znamenite, najbolj poučne in odločujoče (736). Toda odločilna vprašanja resnične izobrazbe se morajo razreševati na univerzitetnih ustanovah. Vendar je sedanja univerza postala dograditev gimnazijske tendence, ki goji predvsem znanstveni čut. Univerza je postala sodišče vsega znanja. Brez globlje tendence pa univerza postaja akademski aparat (740): imamo opraviti z izobraževalnim strojem univerze (»Bildungsmaschine der Universitä $«$ ), v katerem vse kulture vseh časov izginejo. Na univerzi prevladuje »akroamatska«, aristotelska učna metoda: študent samo posluša (739). Položaj študenta je treba meriti ob treh merilnikih (»Gradmesser«), ki so: potreba do filozofije, instinkt za umetnost in grška in rimska antika kot utelešen kategoričen imperativ vsake kulture. Na univerzi prevladuje historična izobrazba, v kateri je naravni filozofski nagon paraliziran, saj se univerza ukvarja s filozofijo na nevtralen način. $V$ sedanjem stanju je filozofija izgnana $z$ univerze in univerza do umetnosti nima pravega odnosa. Če od sodobne izobrazbe in kulture odvzamemo Grke, skupaj s filozofijo in umetnostjo, izgubimo lestev, po kateri bi se še mogli vzpenjati v izobraževanju (744). Sedanji študent, nepripravljen za filozofijo, je brez instinkta za resnično umetnost in je svoboden barbar v primerjavi z Grki. Sočasno psevdo-kulturo Nietzsche šteje za grozljivo posledico napačnega izobraževanja (746).

Prava izobrazba in kultura more biti dosežena samo tedaj, ko so izpolnjeni trije pogoji: to so "vrata filozofije, umetnosti, antike«. Resnična izobrazba je nasprotje akademske svobode, ki zahteva poslušnost, podrejanje, vzgojo. Do nje pa ni mogoče priti brez nove intonacije. Univerza mora postati orkester, ki ga vodi genij. Tak orkester bo gradil red duhov v smeri zaželene nove organizacije univerze: »Ob moji prispodobi pa vi razložite, kaj bi jaz rad razumel kot resnično izobraževalno ustanovo in zakaj jaz niti v univerzi neke takšne ustanove še zdaleč ne prepoznam« (752). 
Dva Nietzschejeva najpomembnejša dosežka sta: kritika tradicionalne klasične vzgoje in kritika novega javnega državnega izobraževanja.

\section{ALBERT CAMUS}

Camus je tisti avtor, ki je v našem času, v moderni, odločno zagovarjal recepcijo grških momentov razlage sveta. Ti momenti naj bodo priklicani v spomin in uveljavljeni nasproti krščanski dediščini in proti miselni in življenjski formi moderne kot korektiv. V Upornem človeku Camus razvije idejo o mišljenju poldneva, la pensée de midi, in sredozemskega mišljenja. Pri tem se je opiral na intuicije svojega filozofskega učitelja Jeana Greniera, ki je v esejih z naslovom Inspirations méditerranéennes (1940) odločilno vplival na Upornega človeka ${ }^{60}$ - ki ga je Camus posvetil prav Grenieru. Pri tem je ključno njegovo predavanje na prvem kongresu Académie Méditerranéenne v Monaku z naslovom »L'humanisme et la Méditerranée«. Grški svet vsebuje potrjevanje življenja v fizično-čutni polnosti in instanco reda kot dajanje meje in smisla, ki človeka obvaruje pred hybrisom antropomorfizma: »Samo antika mi je odprla oči« (Sagesse de Lourmarin). ${ }^{61}$

V Upornem človeku je Camus opisal sodobno zahodnoevropsko kulturo kot nihilistično. Korenine nihilizma vidi v pretiranih poskusih, da bi ustvarili bolj človeški svet. Te poskuse opiše pod naslovi metafizična in zgodovinska revolta. Bistvo nihilizma je sistematično neupoštevanje meja človeške narave, kar lahko pelje do zgodovinskih zločinov in rušenja samih pogojev za človeško bivanje v svetu. Camus išče pozitivno etiko onstran nihilizma. Proti poveličevanju zgodovine in zaničevanju narave postavlja »antično ljubezen do kozmosa« (235). Antično mišljenje pozna »lepo ravnovesje človeškega in narave«. Grška misel je »tradicija prijateljstva s svetom«. Nihilistično fabriciranje sveta po meri subjekta more preseči samo umetnost, ki ima nenavadno zmožnost, da ustvarja red v neredu časa; to pa dosega s svojim nagovorom človeške narave $\mathrm{v}$ njeni telesni in čutno-čustveni razsežnosti. Umetnost ima zmožnost, da oblikuje čustva in strasti sodobnikov in jih spravi v formule (338).

Camusova filozofija si prizadeva - po sledeh Nietzschejevih uvidov - preseči nihilizem z umetnostjo. Umetnost je tista zmožnost, ki v nihilistični svet vnese kreativnost, s katero premaga nihilizem: »Umetnost nas nauči vsaj to, da človek ni povzet samo v zgodovini in da najde svoj razlog biti tudi v redu narave« (341). Tisto, kar daje dostojanstvo bivanju in svetu, je lepota. Nova morala je zmožna stalno odklanjati krivico in ne neha "pozdravljati človekovo naravo in lepoto sveta« (341).

Bistvo nihilizma je v tem, da ne upošteva kvalitete in meja človeških dejanj: »Ko odstranjuje vsak princip upanja, nihilizem zavrača vsako mejo« (418). Na ta

60 Yadel, »Jean Grenier«, 21.

${ }_{61}$ Citirano po Yadel, »Jean Grenier«, 30. 
način Camus povzema Aristotelovo idejo uravnavanja temeljnih razpoloženj preko Nemesis. Nemesis je idealna boginja, ki skrbi za pravično delitev, istočasno pa je boginja nejevolje spričo krivice ali človeške neumerjenosti. V poglavju »Mera in nezmernost« (429 in sl.) govori o tem, kako najti mero. Zgodovinska dialektika mora najti svojo mejo, ki je njena prva »vrednota«: »Heraklit, ki je odkril postajanje, je vendarle dal mejo temu neprestanemu odtekanju. To mejo so simbolizirali v Nemezis, boginji mere, ki je smrtonosna za tiste, ki prekoračijo mero. Misel, ki bi hotela upoštevati sodobna protislovja revolte, bi morala to boginjo prositi za svoj navdih« (431). Nihilizma ni mogoče preseči brez obnove »sredozemskega duha« (369). Protiutež nihilizma je »opoldanska misel«, je sredozemska dediščina: to je »duh, ki meri življenje, je tudi tisti duh, ki oživlja dolgo izročilo tistega, kar bi mogli imenovati sončno misel in kjer je bila, od Grkov dalje, narava vedno uravnotežena s postajanjem « (433). Moderni prenos poudarka na zgodovino je škodoval naravi in uničil samo mejo. Narava, ki preneha biti predmet opazovanja in občudovanja, ne more biti naposled nič drugega kot snov dejavnosti, ki jo meri na njeno spremembo (370). Zato je v njegovi etični teoriji Zemlji dosojen mitičen pomen. Iz zemlje človeška beseda prejme svoje številne prebliske o svetu, ki, tostran racionalnega univerzuma, ki ga zaradi njega moremo graditi, »ostaja naša prva in zadnja ljubezen« (Uporni človek, 441).

Glede Camusovega novega razumevanja kulture se je treba opreti na njegovo malo zbirko esejev Poletje (1954). Camus sedaj navezuje na Nietzschejevo kritiko evropske zgodovinske zavesti. Evropa je preveč polna tradicije, evropski kulturni centri trpijo od historizma: »Mesta, ki jih Evropa more nuditi, so preveč polna govoric o preteklosti.« (105)

V eseju »Helenino izgnanstvo« (1948) opomni na to, da moderni svet ne pozna prave lepote: »Izgnali smo lepoto, Grki so zaradi nje prijeli za orožje« (141). Za razliko od evropskega Zahoda ima mediteranski svet drugačen občutek za lepo: »Mediteran ima svojo sončno tragiko, drugačno od tragike megle« (141). Poleg tega razvija temo zemlje in kritizira nihilizem tehnike: »Na pijanem nebu prižigamo sonca, ki jih mi hočemo« (142). Moderni svet hoče gospodovati zemlji in nebu: »Obrnili smo hrbet naravi ... Zato je danes nedostojno razglašati, da smo sinovi Grčije« (142-143). Zgodovinska dejavnost ne more razložiti niti naravnega univerzuma, ki je obstajal pred njo, niti lepote, ki je nad njo. Boj za svobodo mora postati istočasno "prizadevanje za lepoto« (144). Samo ob upoštevanju lepote je naše moralno prizadevanje na pravi poti preoblikovanja sveta, ki ostaja temeljna naloga za vsako generacijo. Moremo se boriti proti pojavom absurda in živeti v horizontu mere samo na ta način, da se navežemo na Grke z njihovim čutom za lepo. Kje srečamo Grke: „Priznana nevednost, zavračanje fanatizma, meje sveta in človeka, ljubljeni obraz, skratka lepota: to je polje, kjer spet pridemo skupaj z Grki« (145). Camus je mogel iti preko nihilizma samo v luči klasične grške kulture. Prišteval se je med ljudi, ki jih je opisal 
kot »nevredne, toda trmasto zveste sinove Grčije, ki so ostali živi v tem suhoparnem stoletju« (152).

\section{HANNAH ARENDT}

Eseji Hane Arendt Med preteklostjo in prihodnostjo postavljajo fenomen vzgoje v zgodovinsko perspektivo.

V eseju »Kriza v vzgoji« izhaja iz dejstva, da v sodobnem svetu kriza vzgoje postala "političen problem prvorazredne velikosti« (179). K posebnemu pomenu vzgoje v moderni družbi je prispevalo ameriško navdušenje za vse novo in zaupanje $\mathrm{v} »$ neomejeno perfektibilnost« (Tocqueville). Vzgoja ima namreč opraviti z otroki, otroci pa so »novi po rojstvu«. In otroke, ki vstopijo v skupnost odraslih kot mladi ljudje, so Grki imenovali oi véoı (182). Doslej je bila vzgoja v politiki aktualna samo v političnih utopijah, ki so slonele na predpostavki, da odraslih ne moreš več vzgajati, otroke pa vzgajaš, da jih oblikuješ po svoji meri, kakor je to storil Platon v državi. Toda gojenci za utopični jutri de facto niso svobodni državljani. Utopije ne vidijo, da je v sami naravi človeškega stanja, da se vsaka nova generacija vključuje v star svet. Vzgajati za nov svet je contradictio in adiecto: utopije vzamejo novim njihovo lastno priložnost za novo. V politiki in v vzgoji mora zato prevladati »zdrav človeški razum,« ki je v resnici tisti »skupni čut«, preko katerega smo z vsemi čuti »skladni z enim svetom, ki je skupen nam vsem« (184). V vsaki krizi je uničen kos sveta, nekaj, kar je skupno nam vsem. Kriza v vzgoji je težavna, ker kaže na probleme napredne vzgoje in kaže na problematiko sodobne množične družbe. Princip »izenačevanja« se je v ameriški vzgoji uresničil za ceno učiteljeve avtoritete in na stroške nadarjenih dijakov.

Arendtova razlikuje tri temeljne domneve, ki povzročajo krizo vzgoje. Prva je, da obstaja avtonomni otroški svet; to vodi od avtoritete odraslih k avtoriteti skupine, ki je vedno »opazno močnejša in bolj tiranska« kot avtoriteta individualne osebe: Hannah Arendt jo imenuje »tiranija večine« (187).

Druga domneva, ki jo je treba upoštevati v sedanji krizi, se nanaša na poučevanje. Pedagogika je postala znanost o poučevanju nasploh in se je osamosvojila od dejanske snovi, ki jo je treba poučevati. Tako pride do izginotja učitelja, ki ni avtoritaren in ki bi imel avtoriteto na osnovi znanja. Temu fenomenu Hannah Arendt reče prevlada pedagogike nad stroko (187).

Poleg tega naj se ne uči, temveč naj se posreduje savoir-faire, kar pomeni, da naj šola ne poučuje védenja, temveč spretnosti. Zato se učenje nadomešča $z$ delom, delo pa $\mathrm{z}$ igro. Na ta način sta privajanje na delo in priprava na vstop v svet odraslih izbrisana v imenu avtonomije »sveta otroštva« (188). Na ta način je otrok izključen iz sveta odraslih. Zato je probleme vzgoje treba opazovati v širšem horizontu, kar 
pomeni osvetliti vlogo vzgoje v vsaki civilizaciji, se pravi, kakšne obveze ima vsaka človeška družba do otrok.

Kriza izobraževanja je odsev splošne krize in nestalnosti moderne družbe.

Učenec je nov v tujem svetu in je hkrati novo človeško bitje. Tako je otrok v odnosu do sveta in v odnosu do življenja. Poleg spočetja in rojstva starši otroke tudi vpeljejo v svet. V vzgoji imamo odgovornost za »razvoj otroka in za kontinuiteto sveta« (190).

Družina ima nalogo, da otroka zavaruje pred svetom. Otrok rabi »varnost teme«, da sploh raste in pride do zrelosti. Otroškega življenjskega prostora ne smemo spremeniti »v neke vrste svet.« Vendar moderna družba razveljavlja razliko med tem, kaj je privatno in kaj je javno; starim vzgojnim metodam je namenjen očitek, da so otroke jemale kot majhne odrasle, obenem je družina izpostavljena svetlobi javnega sveta: med obe področji pa je sedaj vpeljana družbena sfera. In izobraževanje je ravno ustanova, ki je umeščena med sfero družine in javno sfero politike.

Šola je institucija med domom in svetom, ki omogoča prehod od družine v svet. Vzgojitelji vpeljujejo mlade v nenehno razvijajoči se svet. Te naloge pa ni mogoče izvajati brez avtoritete: $» \mathrm{~V}$ izobraževanju ta odgovornost za svet prevzame obliko avtoritete« (193). Danes ima avtoriteta v javnem življenju »izjemno sporno vlogo« (194), ker nočemo nikomur delegirati odgovornosti za svet ali pa sami zavračamo zahtevo in potrebo po urejenosti sveta.

Starševsko ali pedagoško zavračanje odgovornosti za svet je simptom »moderne odtujenosti od sveta" (195). K vzgoji bistveno spada konservativizem, kolikor konservacija pomeni ohranitev. Konservativizem pa je v politiki poguben, ker vodi k uničenju: politični svet se mora vedno znova graditi. V osnovi vedno vzgajamo za svet, ki je »vržen s tečajev« (196). Vsaka vzgoja mora biti ohranjevalna, ker je v vsakem otroku nekaj »novega in revolucionarnega« (196). Poleg tega je današnji svet s stališča naslednje generacije vedno star. Toda vzgoja mora biti konservativna, da se novo more razvijati.

Kriza avtoritete v vzgoji je tesno povezana s krizo tradicije, tj. s krizo našega odnosa do preteklosti (196). Kriza tradicije je za vzgojitelja še posebej občutna, ker mora posredovati med starim in novim, tako da že njegov poklic zahteva »izredno upoštevanje preteklosti«. Glede preteklosti je velika razlika med Rimom in Grčijo. Rim slavi preteklost, za Grke pa sta bit in pojav isto. Tako je Goethe dejal, da starati se pomeni "postopen umik iz sveta pojavov« (197). Za Grke sta bit in pojavljanje isto.

Antična vzgoja je bila enotnost, vzgoje, etike in politike. V njej nastopa nenavadna povezava med prijateljstvom, tovarištvom in avtoriteto, ki je danes ni. Vzgajati je v antiki pomenilo »omogočiti, da si povsem vreden svojih prednikov« (Polibij). Moderna kriza ne dovoljujeje povratka nazaj. Problem vzgoje danes je v tem, da se vzgoja ne sme odreči ne avtoriteti ne tradiciji, četudi v širokem političnem svetu ne veljata ne avtoriteta ne tradicija. Zato je treba področje vzgoje ločiti od javnega in 
političnega življenja, da bi mogli aplicirati primerno avtoriteto, primeren odnos do preteklosti. Da bi vzgojitelj mogel učiti otroke, kakšen je svet, se mora vračati tudi v preteklost. Upoštevajoč specializacijo znanja pa vzgoja ne vpeljuje v »svet kot celoto« (196), temveč v določen segment. Prav tako nič več ni mogoče, da bi samo vzgajali, ne da bi istočasno poučevali (196).

Je pa nekaj, česar ni mogoče prenesti na posebno znanost pedagogike, to je naša drža do »dejstva rojstvenosti« (196). Na svet pridemo z rojstvom, in ta svet se stalno

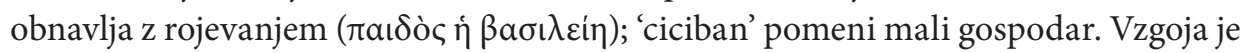
točka, kjer odločamo, ali dovolj ljubimo svet, ali imamo dovolj radi naše otroke, da jih pripravimo »Za nalogo obnavljanja skupnega sveta« (196).

Vzgojna dejavnost pomeni »človeško zmožnost da skrbi za svet«(100-101). Za oblikovanje sveta pa ima poseben pomen umetnost. O vlogi umetnosti v sodobni politični stvarnosti Hannah Arendt govori v eseju »Kriza v kulturi«. Hannah Arendt išče svetovno dimenzijo v dobi množične družbe, ki jo vodi potrošništvo. Pri tem je pozorna na vlogo kulture in zlasti umetnosti v množični družbi. Pri umetniku je ne zanima toliko njegov subjektivni individualizem kot dejstvo, da ustvarja umetniška dela kot najvišje kulturne predmete (204). V 19. stoletju so umetniki družbo običajno obtoževali »filistrstva« (204), ocenjevanje vsega »v pojmih neposredne koristnosti in materialnih vrednot $«$. Toda fenomen postane kompleksen s pojavom kulturnega ali izobraženskega filistra (206): ta fenomen je poznan kot »razvrednotenje vrednot«. Kulturno filistrstvo nas postavi pred nalogo, da odkrijemo nekega velikega avtorja preteklosti brez pomoči tradicije ali »celo proti tradicionalnim standardom« (208).

$\mathrm{V}$ moderni industrijski družbi je fenomen kulture treba videti v povezavi $\mathrm{s}$ "praznim časom« (209-210). Moderna množična kultura ni sovražna umetniški produktivnosti (210), problem pa je $\mathrm{v}$ tem, da v množični družbi kulturni predmeti izginejo v potrošnji. Umetniška dela presegajo krogotok življenjskega procesa, ker se nanašajo na »fenomen sveta (211). Lepota umetniških del je, da segajo čez čas, v katerem so nastala, nikoli pa ne presegajo sveta: $\mathrm{v}$ tem smislu je posvetna celo religiozna umetnost. Zaradi svoje trajnosti so umetnine »najbolj svetne od vseh stvari« (212) in obratno svet dobi svojo trajnost preko kulture oz. umetnosti. Toda svet nastane šele z umetnostjo. Razlikujoč delo kot napor, delo kot izdelek in delo kot dejanje - Arbeit, Werk in Handlung - Arendtova daje umetnosti ta pomen, da pokaže formo stvari. Forma stvari je to, preko česar se stvari prikazujejo. Umetnine so tu z edinim ciljem, ki je "pojav, pojavljanje« (213). Edini kriterij za presojo pojavljanja pa je lepota. Temeljna teza Arendtove je, da potrošniška družba »ne more vedeti, kako skrbeti za svet in stvari« (214).

Razliko med kulturo in umetnostjo Arendtova pojasnjuje z rimskim pojmom kulture. Zgled take kulture je zanjo Ciceronov humanizem, kakor je navzoč v delu Tusculanae disputationes. Ciceronov humanizem je cultura animi, ${ }^{62}$ ki prevaja grško

62 Tusc. 2.5.13. 
$\pi a ı \delta \varepsilon i a$ in pomeni okus, občutljivost za lepoto in »ljubezen do lepote« (216). Mero te ljubezni določa politika (Tukidid). Kultura in politika sta soodvisni. Ta soodvisnost temelji v na načinu mišljenja, ki ga je Kant imenoval razsodna moč ali presodnost

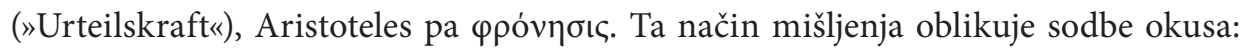
»Okus presoja svet po njegovem pojavu in njegovi svetovnosti« (227). Sodbe okusa so osnova humanizma in kulture: »Okus debarbarizira svet lepega« (226).

Tako je Hannah Arendt poskusila vzpostaviti skladnost med vzgojo, politiko, umetnostjo in našim bivanjem v svetu.

\section{ZAKLJUČNA OPOMBA}

Pri obravnavi pomena antične vzgoje za sodobno problematiko izobraževanja smo vzeli za izhodišče Aristotelovo filozofijo, ker je njegova teorija filozofske izobraženosti poskušala razmejiti med znanostjo, umetnostjo, vzgojo in filozofijo. Kadar je kultura zmožna postaviti ta razmerja, jo Aristotel imenuje »arhitektonsko mišl-

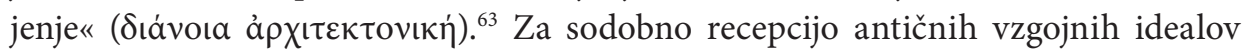
sem $v$ tej razpravi na kratko predstavil tri precej različne avtorje: filozofa in filologa Nietzscheja, filozofa in književnika Alberta Camusa in politično filozofinjo Hanno Arendt. Vsem njim je skupno to, da sodobno zgodovino, umetnost in politiko dojamejo v tesni navezavi na grško antiko, še več, ponovitev grške antike je temeljna supozicija njihove dejavnosti in temelj sodobne zgodovinske zavesti. Zdi se mi, da je njihovo izhodišče v razmišljanju v vzgoji in kulturi mogoče povzeti s Heideggrovim stavkom, ki je bil izrečen v njegovi recenziji Jaspersa in ki je postavljen za moto: »Svet brez sveta Grkov je katastrofa.«Za Nietzscheja je navezava na antiko podlaga za merjenje sodobnosti, Camus skuša dati književnosti status modrosti, ki ga je imela v antiki, medtem ko Hannah Arendt vzgojo opazuje z eksistencialnega vidika našega odkrivanja in oblikovanja sveta. Advokatski odnos do antične grške filozofije in umetnosti, najbolj razviden pri Camusu, je treba razumeti v luči fenomenološkega (Husserlovega) razumevanja kulture v njeni stopnjeviti zgodovinskosti, kakor je bilo izpostavljeno v uvodnem paragrafu.

\section{BIBLIOGRAFIJA}

Arendt, Hannah. Med preteklostjo in prihodnostjo. Šest vaj v političnem mišljenju. Prev. Vlasta Jalušič idr. Ljubljana: Krtina, 2006.

Ballauff, Theodor in Gert Plamböck. PÄDAGOGIK. Eine Geschichte der Bildung und Erziehung. Band 1, Von der Antike bis zum Humanismus. Freiburg in München: K. Alber, 1969.

63 EE 1.6.1217a 6-7 
Camus, Albert. L'Été. Paris: Gallimard, 1954.

—__ L' Homme révolté. Paris: Gallimard, 1951.

- Mit o Sizifu. Prev. Janez Gradišnik in Zoja Skušek-Močnik. Ljubljana: Cankarjeva založba, 1980.

___ Izbrani eseji. Prev. Jože Javoršek. Ljubljana: Cankarjeva založba, 1998.

Dilthey, Wilhelm. Pädagogik, Geschichte und Grundlinien des Systems. 3. izd. Stuttgart: B. G. Teubner, 1960.

Fortin, Ernest-L. „Die Paradoxien der aristotelischen Bildungstheorie im Lichte neuer Diskussionen.« V: Erziehung und Bildung in der heidnischen und christlichen Antike, ur. Horst-Theodor Johann, 252-71. Darmstadt: Wissenschaftliche Buchgesellschaft, 1976.

Heidegger, Martin. Reden und andere Zeugnisse eines Lebensweges, 1910-1976. Ur. Hermann Heidegger. Frankfurt: Klostermann, 2000.

Husserl, Edmund. Die Krisis der europäischen Wissenschaften und die transcendentale Phänomenologie. Ur. Walter Biemel. 2. izd. Haag: Martinus Nijhoff, 1976.

___ Die Krisis der europäischen Wissenschaften und die transcendentale Phänomenologie, Ergänzungsband - Texte aus dem Nachlass 1934-1937. Ur. Reinhold N. Smid. Dordrecht: Kluwer, 1993.

___ _ . _ Vprašanje po izvoru geometrije kot intencionalno-zgodovinski problem.« Prev. Uroš Grilc. Problemi 36, št. 1-2 (1998): 7-29.

Lichtenstein, Ernst. »Aristoteles: Über Erziehung.« V: Erziehung und Bildung in der heidnischen und christlichen Antike, ur. Horst-Theodor Johann, 319-36. Darmstadt: Wissenschaftliche Buchgesellschaft, 1976.

Meister, Richard. »Die Entstehung der höheren Allgemeinbildung in der Antike. V: Erziehung und Bildung in der heidnischen und christlichen Antike, ur. HorstTheodor Johann, 22-30. Darmstadt: Wissenschaftliche Buchgesellschaft, 1976.

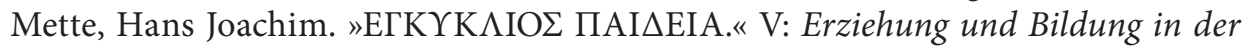
heidnischen und christlichen Antike, ur. Horst-Theodor Johann, 31-41. Darmstadt: Wissenschaftliche Buchgesellschaft, 1976.

Nietzsche, Friedrich. Die Geburt der Tragödie. Unzeitgemäße Betrachtungen 1-4. Nachgelassene Schriften 1870-1873. Ur. Giorgio Colli in Mazzino Montinari. Berlin in New York: De Gruyter, 1988.

___ Vesela znanost. Prev. Janko Moder. Ljubljana: Slovenska matica, 2005.

Thouard, Denis. "Le centaure philologique: Nietzsche entre critique et mythe.« V: Nietzsche, ur. Marc Crépon, 155-74. Paris: Herne, 2000.

Yadel, Martina. »Jean Grenier, 'méditerranéen d' adoption' - Freund und Lehrer von Albert Camus."V: »Helenas Exil."Albert Camus als Anwalt des Griechischen in der Moderne, ur. Heinz Robert Schlette in Franz Joseph Klehr, 17-41. Rottenburg in Stuttgart: Akademie, 1991.

Willmann, Otto. Aristoteles als Pädagog und als Didaktiker. Berlin: Verlag Von Reuther und Reichard, 1909. 


\section{ON THE CONTEMPORARY RELEVANCE OF GREEK PAIDEIA \\ TO THE CONCEPT OF A BALANCED EDUCATION: ARISTOTLE, NIETZSCHE, CAMUS, H. ARENDT}

\section{SUMMARY}

Contemporary education systems are in a constant process of restructuring, thus requiring philosophy to reconsider the basic assumptions of education. The phenomenon of education can only be defined and clarified historically, i.e. with reference to the ancient Greek paideia. The Greek culture created a comprehensive system of both education and pedagogy as a theory of education, teaching, and knowledge (Dilthey).

(1) A phenomenological approach to Aristotle's pedagogy. Aristotle's theory of physical, moral, and political education (Nicomachean Ethics and Politics) is founded upon the notion of the natural development of every being. In addition, Aristotle creates the concept of philosophical pedagogy. A philosophically educated person (ho pepaideumenos) has the competence to treat problems emerging with the formation of particular sciences, and to reflect on the method of each scientific discipline. This philosophical culture is also connected with dialectic, rhetoric, and politics.

(2) Nietzsche's ideas on education and culture are presented in two of his early works: On the Future of Our Educational Institutions and We Philologists. In his criticism of the German education system of his time, he explains his basic historical assumption that the real homeland of education is the Hellenic world. A restructuring of the education system cannot be carried out without the Greek and Roman antiquity as the embodied categorical imperative of all culture. A general education which disregards antiquity is considered barbaric. However, Nietzsche's philosophy of education remains unfinished, giving no definite conclusions.

(3) Camus' philosophy describes the modern West European culture as nihilistic. The essence of nihilism is a systematic ignorance of the limits of human nature, which can lead to historical crimes and to destroying the conditions for the human existence in the world. The formation of a world that will not be subdued by the logic of nihilism is possible only through artistic creativity. His 'solar' or Mediterranean thought, giving special emphasis to nature, measure, and beauty, is a revival of Greek philosophy.

(4) In her essays Between Past and Future, Hannah Arendt studies the contemporary crisis of education. She distinguishes three causes for the crisis: the assumption of an autonomous child's world, the predominance of pedagogy over knowledge, and the teaching of skill rather than of knowledge. Every education system must bear responsibility for the development of the child as a person, at the same time ensuring the continuity of the world. The phenomenon of refusing responsibility for the world 
is a symptom of estrangement. In her view, education is where it is up to us to decide whether we love the world and our children enough to prepare them for the task of renewing a common world. 